\title{
Anomalous sub aortic left brachiocephalic vein: a case report* $^{*}$
}

\author{
Veia braquiocefálica esquerda subaórtica anômala: relato de caso \\ Vetri Sudar Jayaprakasam ${ }^{1}$, Santosh Gurudev ${ }^{1}$, Klaus Irion ${ }^{2}$, Ali Nawaz Khan ${ }^{3}$, Andrew R. Pettit ${ }^{4}$
}

\begin{abstract}
The left brachiocephalic vein occasionally follows an aberrant course. It is usually associated with congenital cardiac anomaly. We present a case of anomalous left brachiocephalic vein which followed a sub aortic course, with no cardiac abnormality. Multi detector computed tomography is very useful in accurate diagnosis of this condition and prevents any further investigation in cases of isolated abnormalities.

Keywords: Anomalous left brachiocephalic vein; Mediastinal mass; Computed tomography; Chest.
\end{abstract}

Resumo A veia braquiocefálica esquerda, ocasionalmente, segue curso aberrante. Esta variação freqüentemente está associada com anomalias congênitas do coração. Neste trabalho é apresentado um caso de veia braquiocefálica esquerda anômala, com trajeto subaórtico, sem anormalidade cardíaca. A tomografia computadorizada com multidetectores é muito útil no correto diagnóstico dessa condição e permite a conclusão diagnóstica, sem quaisquer outras investigações.

Unitermos: Veia braquiocefálica esquerda anômala; Massa mediastinal; Tomografia computadorizada; Tórax.

Jayaprakasam VS, Gurudev S, Irion K, Khan AN, Pettit AR. Anomalous sub aortic left brachiocephalic vein: a case report. Radiol Bras. 2008;41(2):135-137.

\section{INTRODUCTION}

The anatomy of the great vessels in the mediastinum is complex and therefore prone for anomalies. These are usually associated with congenital heart disease. Aberrant right subclavian artery associated with a left aortic arch is the most common vascular anomaly in the mediastinum ${ }^{(\mathbf{1})}$. Persistent left superior vena cava is the commonest venous anomaly with an incidence of approximately $0.3 \%$ in the general population and $3-5 \%$ in congenital heart disease patients ${ }^{(2)}$. An anomaly of the brachiocephalic vein is rare and is usually associated with cardiac anomalies seen in approximately $0.2 \%$ to $1 \%$ of congenital heart anomalies ${ }^{(3)}$. Isolated anomaly of the

\footnotetext{
* Study developed at The Royal Liverpool University Hospital, Liverpool, United Kingdom.

1. Residents, Radiology Residents (Specialist Registrar in Radiology) Mersey Rotation, Liverpool, United Kingdom.

2. PhD, Consultant Radiologist at the Cardiothoracic Centre Liverpool and The Royal Liverpool University Hospital, Liverpool, United Kingdom.

3. Member of the Royal College of Surgery, Fellow of the Royal College of Radiology, United Kingdom. Charmain Imaging, King Abdulaziz Medical City, Riyadh, Kingdom of Saudi Arabia.

4. Member of the Royal College of Physicians, and of the Roya College of Pathologists, Professor of Haematology, Royal Liverpoo University Hospital, Liverpool, United Kingdom.

Mailing address: Dr. Klaus Irion. 912 Manchester Road, Bury. Postcode: BL9 8DW, United Kingdom. E-mail: klaus.irion@ btinternet.com

Received November 12, 2007. Accepted after revision January 8, 2008.
}

left brachiocephalic vein (LBCV) is even rarer. With the advent of non-invasive technologies like multi detector computed tomography (MDCT) and magnetic resonance (MRI), there is now an increase in diagnosis of these anomalies. These are usually asymptomatic and the importance of diagnosing this condition is mainly to understand the anatomy during vascular access and mediastinal surgeries. In patients with no other cardiac abnormality, this anomaly may be found incidentally whilst investigation of other causes.

The purpose of this work was to describe this rare case of an anomalous left brachiocephalic vein (ALBCV) in a patient with no other cardiac abnormality, investigated with a MDCT with three dimensional reconstructions (3D).

\section{CASE REPORT}

A 34 year old male patient with a history of heavy smoking was investigated for lymphocytosis.

An initial chest X-ray (Figure 1) showed mild mediastinal widening which raised the suspicion of an anterior mediastinal mass. A computed tomography (CT) scan of the chest was performed for further evaluation

Figure 1. Chest radiograph showing mild mediastinal widening (arrow).

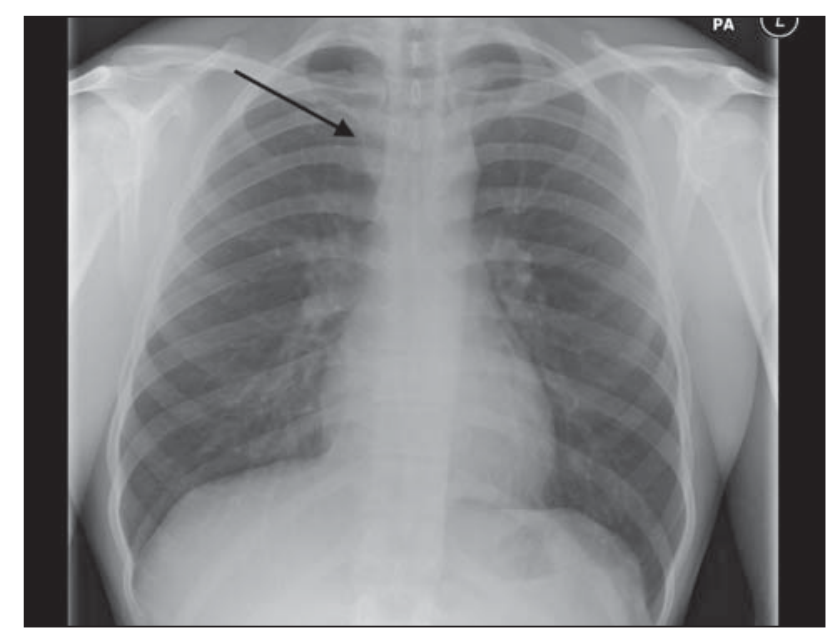




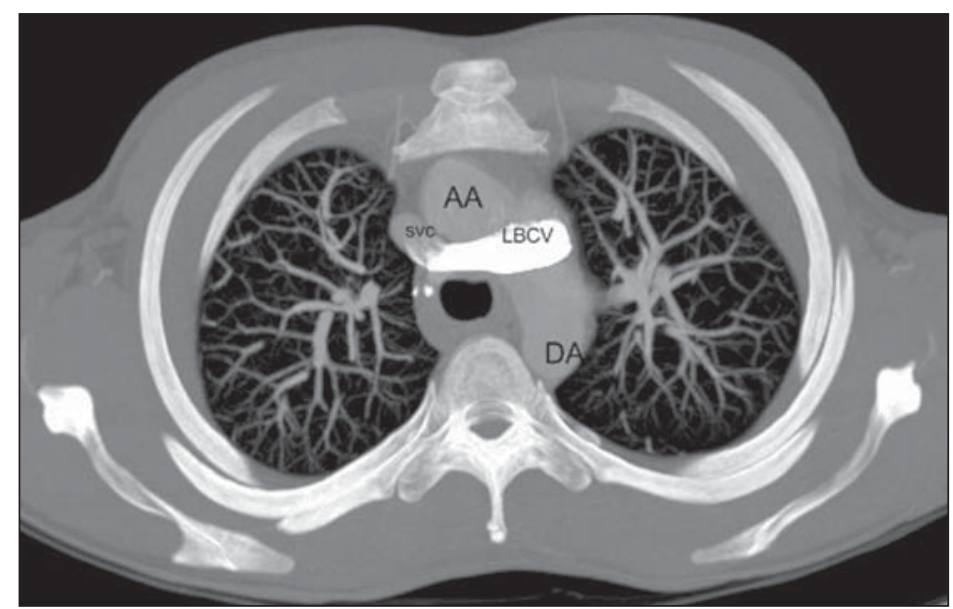

Figure 2. CT images of the anomalous left brachiocephalic vein showing sub aortic position. A: Axial view. B: Sagittal view. C: Coronal view. The ascending aorta (AA) is in front of the left brachiocephalic vein (LBCV). The left pulmonary artery (PA) is below the LBCV that is crossing from the left to the right to merge with the right brachiocephalic vein (RBCV) to form the superior vena cava (SVC). The descending aorta (DA) lies behind.

A
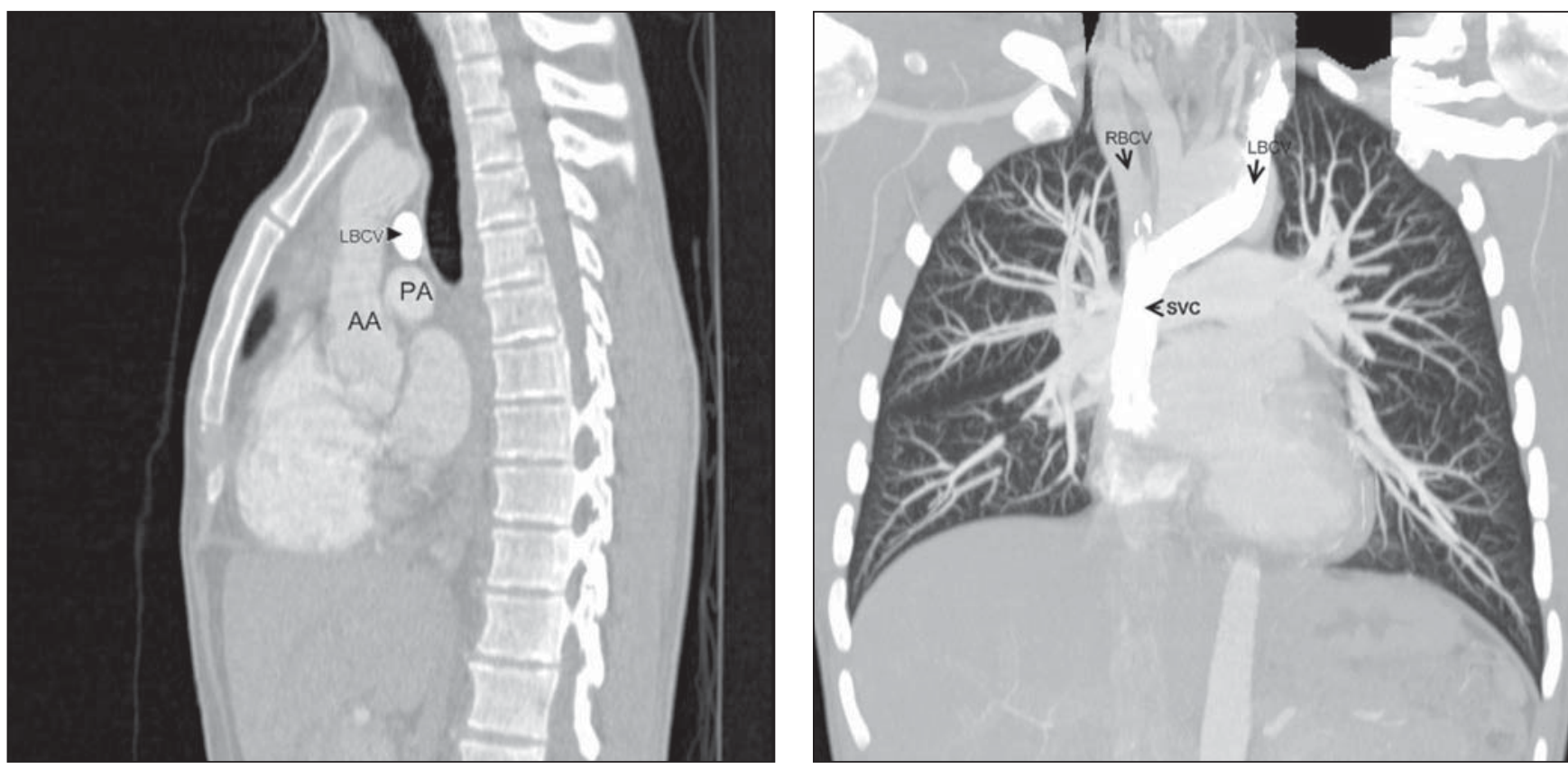

B

C

of the widened mediastinum in this patient with lymphocytosis. The CT revealed an ALBCV (Figure 2). The LBCV followed an obliquely downward course behind the ascending aorta and joined the right brachiocephalic vein forming the superior vena cava (Figure 3). The right brachiocephalic and the superior vena cava had normal anatomy. No other cardiac anomaly was found in this patient. No further investigations or treatment were carried out for the ALBCV.

\section{DISCUSSION}

The LBCV is one of the major venous structures within the mediastinum. It is formed by the union of left subclavian and left internal jugular vein just behind the sternal end of left clavicle. It runs downward and to the right side behind the upper part of manubrium sterni, anterior to the three branches of the arch of aorta and terminates just behind the first right costal cartilage by uniting with the right brachiocephalic vein, forming the superior vena $\operatorname{cava}^{(4)}$.

The normal anatomy and the course of the major veins within the mediastinum are very much dependent on its embryological development. Under the normal circumstances of fetal development, there are paired anterior cardinal veins that drain the upper body and the extremity. Around eighth week of the embryonic development, transverse channel forms between the right and left anterior cardinal veins which later develops into the left brachiocephalic vein. It is postulated that instead of a single transverse channel, there is formation of venous plexus between the anterior cardinal veins which communicate with each other in cephalo caudal as well as ventral dorsal directions. The surrounding arterial systems are developed between the fourth and seventh week of embryonic life. Normal development and enlargement of the aortic arch and the pulmonary arteries exert pressure on the surrounding inferior dorsal venous plexus which regresses and the blood is directed to the superior 


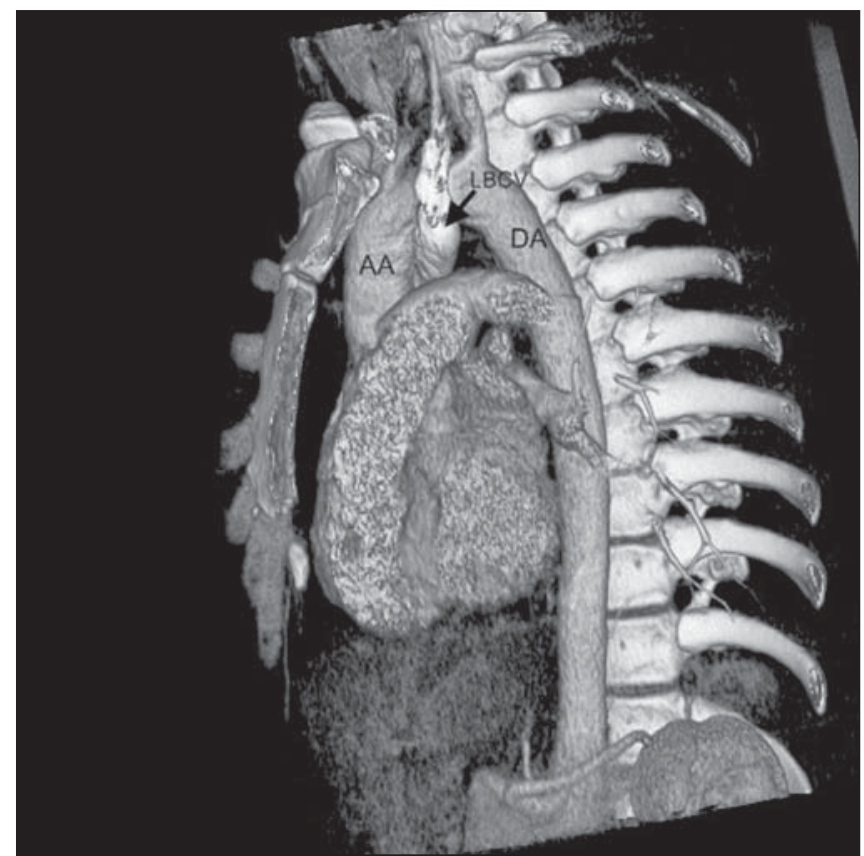

A

Figure 3. Volume rendering processing of the CT data was used to create the 3D images demonstrating the anomalous course of the LBCV. A: Oblique sagitta view after removing the left chest wall. B: Coronal view after removing the anterior thoracic wall. Ascending aorta (AA), arch of aorta (AOA) descending aorta (DA), left brachiocephalic vein (LBCV), pulmonary artery (PA), right brachiocephalic vein (RBCV), superior vena cava (SVC).

ventral portion. The proximal part of the left cardinal vein disappears completely. The distal portion contributes to the formation of left superior intercostal vein. The proximal part of the right anterior cardinal vein forms the superior vena cava ${ }^{(3)}$.

In contrast, when there are anomalies of the development of arch (e.g., right sided arch) or the pulmonary arteries (atresia or stenosis) this can cause sparing of the inferior dorsal portion of the venous plexus and regression of superior ventral portion. This leads to the development of anomalous course of the brachiocephalic vein. However the exact mechanism, cause or correlation between these anomalies has not yet been established ${ }^{(\mathbf{3})}$.

There are at least four major patterns of anomalous course of LBCV described by Takada et al. ${ }^{(5)}$. Most of these anomalies are associated with right sided arch. The LBCV can cross the midline above the aortic arch in between the cephalic vessels. It can cross the midline beneath the aortic arch, above the pulmonary artery, as in our patient Both these can be combined in one patient. The fourth pattern is where the LBCV is beneath the aortic arch, above the pulmo- nary vein and behind the patent ductus arteriosus.

From the radiology point of view, diagnosis of an ALBCV is mainly to avoid misinterpretation of this structure. On an unenhanced CT scan, it can be interpreted as enlarged lymph node ${ }^{(6)}$ or a central pulmonary artery. The descending portion of the ALBCV can be interpreted as persistent left superior vena cava. In the presence of the other cardiac anomalies, the diagnosis can become difficult. However with the availability of MDCT, the vascular channel can be traced from its origin to the termination and correctly identified.

From clinical point of view, knowledge of this anomaly is important when performing central venous catheters or cardiac surgeries. For anaesthetist this may cause difficulties in introducing left sided central lines unless they know the anatomy. Surgeons, if not informed already, may not identify the anomalous course which can significantly alter their surgical approach ${ }^{(7)}$.

The ALBCV in itself is asymptomatic and is not significant unless associated with other cardiac anomalies. This case report demonstrates the usefulness of MDCT in demonstrating detailed anatomy of this anomaly and prevents further investigation in asymptomatic cases with no other cardiovascular anomaly.

\section{REFERENCES}

1. Donnelly LF, Fleck RJ, Pacharn P, et al. Aberrant subclavian arteries. Cross-sectional imaging findings in infants and children referred for evaluation of extrinsic airway compression. AJR Am J Roentgenol. 2002;178:1269-74.

2. Bhatti S, Hakeem A, Ahmad U, et al. Persistent left superior vena cava (PLSVC) with anomalous left hepatic vein drainage into the right atrium: role of imaging and clinical relevance. Vasc Med. 2007;12:319-24

3. Chen SJ, Liu KL, Chen HY, et al. Anomalous brachiocephalic vein: CT, embryology, and clinical implication. AJR Am J Roentgenol. 2005; $184: 1235-40$

4. Ellis $\mathrm{H}$. The clinical anatomy of the great veins of the neck. Br J Hosp Med (Lond). 2007;68:M5-

5. Takada Y, Narimatsu A, Kohno A, et al. Anomalous left brachiocephalic vein: CT findings. J Comput Assist Tomogr. 1992;16:893-6.

6. Chern MS, Ko JS, Tsai A, et al. Aberrant left brachiocephalic vein: CT imaging findings and embryologic correlation. Eur Radiol. 1999;9: 1835-9.

7. Ito M, Kikuchi S, Hachiro Y, et al. Anomalous subaortic position of the brachiocephalic vein associated with tetralogy of Fallot. Ann Thorac Cardiovasc Surg. 2001;7:106-8. 